\title{
Placental chorangioma: Silent trouble maker of the fetus and newborn
}

\author{
*T M R Perera ${ }^{1}$, M A M M Jayawardane ${ }^{2}$, G Ranaweera $^{3}$, A M B W M R N N Ekneligoda ${ }^{4}$
}

Sri Lanka Journal of Child Health, 2021; 50(3): 539-541

DOI: http://doi.org/10.4038/sljch.v50i3.9743

(Key words: placental chorangioma, fetus, anaemia, thrombocytopenia)

\begin{abstract}
Introduction
Chorangiomas are non-trophoblastic vascular tumours arising from primitive chorionic mesenchyme $^{1}$.We report a case of a large chorangioma with significant fetal and neonatal complications
\end{abstract}

\section{Case report}

A 38-year-old gravida 2 para 2 mother was found to have a placental growth with increased vascularity suggestive of chorangioma, projecting into the uterine cavity ultrasonically at 11 weeks of gestation. Its diameter was $2 \mathrm{~cm}$. Her pregnancy was complicated with gestational diabetes mellitus at $20^{\text {th }}$ week of gestation. She was followed up with serial ultrasound scans monitoring fetal growth, amniotic fluid volume and placental mass, which grew up to $5 \mathrm{~cm}$ by the $24^{\text {th }}$ week, and middle cerebral artery (MCA) peak systolic velocity for evidence of fetal anaemia. MCA Doppler remained within normal limits and baby's growth was above the $10^{\text {th }}$ centile. Growth of chorangioma was restricted since 24 weeks of gestation. Progressive polyhydramnios was noted from the $26^{\text {th }}$ week onwards. At 37 weeks of gestation, a baby boy was delivered by an elective caesarean section with a birth weight of $2.53 \mathrm{~kg}$ (-2SD to -1SD) and Apgar scores of 10 at 5 and 10 minutes. His birth length and head circumference were $50 \mathrm{~cm}$ (median) and $35 \mathrm{~cm}$ (median to $-1 \mathrm{SD}$ ) respectively. A placental site tumour, $7 \mathrm{~cm}$ in diameter, was noted at

\footnotetext{
${ }^{1}$ Senior Lecturer in Paediatrics, ${ }^{2}$ Senior Lecturer in Obstetrics \& Gynaecology, Faculty of Medical Sciences, University of Sri Jayewardenepura, Sri Lanka, ${ }^{3}$ Senior Lecturer in Pathology, Faculty of Medicine, University of Colombo, Sri Lanka, ${ }^{4}$ Senior Registrar in Paediatrics, Colombo South Teaching Hospital, Kalubowila, Sri Lanka

*Correspondence: tmrperera@yahoo.com
}

https://orcid.org/0000-0002-4700-4418 (Received on 31 July 2020; Accepted after revision on 18 September 2020)

The authors declare that there are no conflicts of interest

Personal funding was used for the project.

Open Access Article published under the Creative Commons Attribution CC-BY (cC) (P) License delivery and was removed en masse. The baby did not show anaemia or jaundice at birth.

Baby developed jaundice and pallor on day two and was transferred to the neonatal intensive care unit (NICU) for further management. Full blood count showed a haemoglobin of $9.4 \mathrm{~g} / \mathrm{dL}$ (normal range $16.5-21.5 \mathrm{~g} / \mathrm{dL}$ ) and a platelet count of $64,000 / \mathrm{cu}$ $\mathrm{mm}$ (normal range 150,000-450,000/cu mm). Total serum bilirubin was $109.8 \mu \mathrm{mol} / \mathrm{L}$ (phototherapy level $190 \mu \mathrm{mol} / \mathrm{L})$. There were no bleeding manifestations or cephalhaematoma noted. Clotting profile included an activated partial thromboplastin time of 39.9 seconds (normal $<55$ seconds) and an International Normalized Ratio of 1.8 (normal $<1.4$ ). Renal profile, serum calcium and magnesium levels were within normal limits. Creactive protein was normal and blood cultures were negative. Reticulocyte count was $12.9 \%$ (normal $<5 \%$ ) and the blood picture revealed evidence of microangiopathic haemolytic anaemia without evidence of haemoglobinopathy or hereditary red cell membrane defects. Baby's and mother's blood groups were $\mathrm{O}$ positive and A positive respectively. Direct Coombs test was negative. Echocardiography revealed an atrial septal defect and a patent ductus arteriosus without cardiomegaly or pericardial effusion. Ultrasound scans of abdomen and brain did not show any capillary or cavernous haemangiomata. Baby was discharged on day five of life following three days of single phototherapy and a transfusion of packed red cells. Post transfusional haemoglobin value picked up to $14.5 \mathrm{~g} / \mathrm{dl}$.

Histology of the placental mass revealed a wellcircumscribed lesion composed of proliferating capillary sized blood vessels without evidence of cellular atypia, increased mitotic activity or necrosis, in keeping with a chorangioma. On follow up visits at 2 weeks and monthly visits thereafter, the baby was thriving well. Anaemia, hyperbilirubinaemia and thrombocytopenia had resolved. 


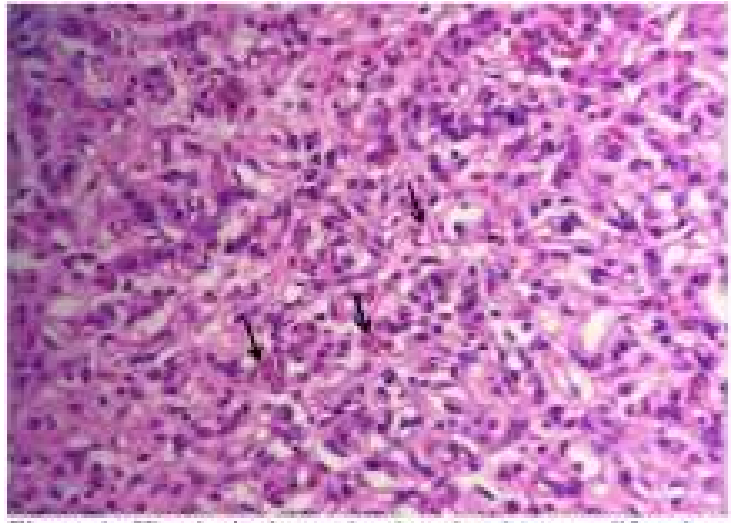

Flqure 1: Histolegdcal examination showing a prodiferarian of capillary sized bood vessels wirh no endidence of cellalor appia, increased mitotic accivity or mecrasis

\section{Discussion}

Placental chorangioma is the most common benign tumour of the placenta ${ }^{2}$. It is caused by capillary dysvasculogenesis during the formation of stem villi and is linked with conditions of lower oxygen tension within the placenta during the second trimester such as increased maternal age, high altitudes and maternal smoking ${ }^{3,4}$. However, in our patient, placental chorangioma was noted ultrasonically in the latter part of the first trimester itself. Chorangioma occurs on the fetal side of the placenta close to the insertion of the cord and is perfused by the fetal circulation ${ }^{3}$. Histologically there are three types namely cellular, vascular and degenerative, the vascular type being the commonest ${ }^{2}$.

Diagnosis is mainly based on ultrasonic demonstration of a hypo- and hyper-echoic mass protruding from the placenta to the amniotic cavity $^{2}$. Differential diagnoses include placental haematoma, partial hydatiform mole, submucosal uterine fibroid, and placental teratoma. Colour Doppler distinguishes it from a placental haematoma ${ }^{5}$. Elevated maternal alpha fetoprotein levels can occur due to seeping of fetal blood into the maternal circulation through tumour capillaries ${ }^{4}$.

Smaller chorangiomas are mainly asymptomatic ${ }^{3}$. The physiological and functional dead space created by chorangiomas larger than $4 \mathrm{~cm}$, especially rapidly growing, could give rise to chronic fetal hypoxia, distress, intrauterine growth restriction, hydrops fetalis and intrauterine death ${ }^{3,4}$. Feto-maternal haemorrhage, microangiopathic haemolysis and haemodilution lead to fetal anaemia as well as thrombocytopenia ${ }^{4}$. Increased urine production due to fetal hyperdynamic circulation or transudation from tumour surface results in polyhydramnios ${ }^{6}$. Gestational diabetes in our case contributed further. Other conditions associated with chorangioma include pre-eclampsia, placental abruption and preterm labour ${ }^{2}$. Beckwith-
Wiedemann syndrome and fetal anomalies such as single umbilical artery and haemangiomas in other sites could occur in concurrence with chorangioma ${ }^{4}$.

A diagnosis of chorangioma warrants frequent fetal monitoring for early identification of fetal cardiac failure and hydrops ${ }^{2}$. Fetal complications peak during the latter part of the second trimester ${ }^{7}$. Prognosis depends on development of fetal complications $^{3,4}$. Prenatal diagnosis of this condition allows early detection and management of possible complications ${ }^{2}$. Early delivery of the baby due to severe fetal complications needs to be balanced against the morbidity and mortality of premature delivery. Fetal blood transfusions could be used to buy time for delaying delivery ${ }^{8}$. Amniodrainage can be used for extreme cases of polyhydramnios $^{8}$. Endoscopic laser coagulation and injection of absolute alcohol have been tried to block the vascular supply to the tumour ${ }^{8}$.

\section{References}

1. Kataria N, Singh A, Bedi PK. Giant placental chorangioma: A rare case report. Journal of Clinical and Diagnostic Research 2016; 10(4): ED03-ED4. https://doi.org/10.7860/JCDR/2016/17222 .7540

PMid: 27190814 PMCid: PMC4866112

2. Ruman U, Chowdhury TS. Placental chorangioma: a case report. Birdem Medical Journal 2012; 2: 113-5. https://doi.org/10.3329/birdem.v2i2.12326

3. Lež C, Fures R, Hrgovic Z, Belina S, Fajdic J, Münstedt K. Chorangioma placentae. Rare tumours 2010; 2(4): e67. https://doi.org/10.4081/rt.2010.e67 PMid: 21234259 PMCid: PMC3019602

4. Amer HZ, Heller DS. Chorangioma and related vascular lesions of the placenta - a review. Fetal and Pediatric Pathology 2010; 29: 199-206. https://doi.org/10.3109/15513815.2010.48 7009

PMid: 20594143

5. Bromley B, Benacerraf BR. Solid masses on the fetal surface of the placenta: differential diagnosis and clinical outcome. Journal of Ultrasound in Medicine 1994; 13(11): 883-6. https://doi.org/10.7863/jum.1994.13.11.88 3

PMid: 7837336 
6. Mara M, Calda P, Zizka Z, Sebron V, Eretova V, Dudorkinova D, et al. Fetal anaemia, thrombocytopenia, dilated umbilical vein and cardiomegaly due to a voluminous placental chorangioma. Fetal Diagnosis and Therapy 2002; 17: 286-92. https://doi.org/10.1159/000063181 PMid: 12169813

7. Zanardini C, Papageorghiou A, Bhide A, Thilaganathan B. Giant placental chorangioma: natural history and pregnancy outcome. Ultrasound in Obstetrics and Gynecology 2010; 35(3): 332-6.

https://doi.org/10.1002/uog.7451

PMid: 19859897
8. Sepulveda W, Wong A, Herrera L, Dezerega V, Devoto JC. Endoscopic laser coagulation of feeding vessels in large placental chorangiomas: report of three cases and review of invasive treatment options. Prenatal Diagnosis 2009; 29: 201-6. https://doi.org/10.1002/pd.2197

PMid: 19156708 